\title{
Reflections on the Process of Researching Disabled People's Sexual Lives
}

\author{
by Kirsty Liddiard \\ School of Disability Studies, Ryerson University
}

Sociological Research Online, 18 (3) 10
<http://www. socresonline.org.uk/18/3/10.html>
10.5153/sro.3116

Received: 11 Feb 2013 Accepted: 3 Jun 2013 Published: 31 Aug 2013

\begin{abstract}
This article offers a reflexive account of the processes, politics, problems, practicalities and pleasures of storying disabled people's sexual lives for the purposes of sociological research. Drawing upon a doctoral study which explored disabled people's lived experiences of sex, intimacy and sexuality through their own sexual stories, the author considers how her identity, subjectivity and embodiment - in this case, a white, British, young, heterosexual, disabled, cisgendered woman with congenital and (dependent upon the context) visible impairment - was interwoven within and through the research methodology; most explicitly, as an interlocutor and co-constructor of informants' sexual stories. Given the paucity of reflexive research in this area, a number of reflexive dilemmas are identified which make important methodological contributions to qualitative sociology, disability studies scholarship and research, and current knowledges of the emotional work of qualitative researchers (Dickinson-Smith et al. 2009).
\end{abstract}

\section{Keywords: Disability, Sexuality, Stories, Storytelling, Reflexivity, Emotion}

\section{Introduction}

1.1 The study which underpins this article explored disabled people's lived experiences of sex and sexuality, intimacy and love. More specifically, the doctoral research, which took place across England, UK, between 2008 and 2011, sought to understand the complex ways in which disabled men and women managed and negotiated their sexual and intimate lives, selves, and bodies in the context of ableist cultures where they are, as Brown (1994: 125) states, assigned the paradoxical social categories of 'asexual, oversexed, innocents, or perverts'. Importantly, the sexual stories told within the research were voiced by disabled people $\left(n=26^{[1]}\right)$ only - in their own ways and on their own terms - thus echoing initiatives found in feminist, anti-racist and disability research methodologies. Such methodologies 'place the minoritised at the centre of analysis' (Dei \& Johal 2005: 2) where their 'subjective experiences and voices' are prioritised (Pole \& Lampard 2002: 290; see also Davies 2000; Shakespeare et al. 1996). This was imperative towards countering the dominant voices within existing research into disabled people's sexual lives which has, paradoxically, mainly been with those who regulate the sexual lives of disabled people (e.g. health professionals, social workers, and support workers) (Shuttleworth 2010). Thus, the intention was to situate disabled people's own voices and lived experiences amongst the myriad of stories told about their lives by 'experts'. Specifically, this was in order to disrupt the paternalistic, professional, patriarchal, and ableist discourses which pathologise, medicalise and psychologise disabled people's (sexual) lives and bodies (Shakespeare et al. 1996; Siebers 2008).

1.2 Conceptualising disabled people's stories as the means through which to explore the intersections of disability and sexuality was embedded in the potential personal and political empowerment of telling stories (Langellier 2001), and the broader notion of sexual stories as instrumental within claims for sexual citizenship (Plummer 1995). Personal empowerment is possible through storytelling, argues Langellier (2001: 700), because 'personal narrative responds to the disintegration of master narratives as people make sense of experience, claim identities, and "get a life" by telling and writing their stories'. As Plummer (1995: 150) advocates, the sexual empowerment and rights of Othered communities depends 'upon a community of stories which make those same rights plausible and possible'. Thus, while the notion of 'empowerment' - particularly within the margins of disability research - remains both contested and contestable (Oliver 1992), the act of telling sexual stories was conceptualised within this study to be 
politically pertinent towards (re)claiming a sexual culture (Siebers 2008), community, and sexual citizenship unconnected to existing disabled sexual cultures and histories. Such cultures and histories, as with those of other sexually Othered bodies which have been subjugated and subjected to discrimination and violence in multiple social and historical contexts (Schilt 2011; Chauncey 1995; Kennedy \& Davis 1993), are 'characterized largely by oppression and discrimination' (Rembis 2010: 53).

1.3 Further, the research was participatory, which is essentially about 'giving more "say" in research to people who are more usually subjected to research' (Swain \& French 2004: 10). With this, and being mindful of my own lived and embodied experiences of disabling environments and systemic ableism, it was imperative that the research process - how to collect stories, how to treat them and what to do with them - be decided, developed and designed in consultation with disabled people. Consequently, a Research Advisory Group (hereby RAG) was established. The RAG was a committed group of local disabled people who actively guided the research from its initial design to the co-production of a dissemination plan following doctoral thesis submission (see Kitchen 2000, 2001). Collectively, the RAG established its own role and aims. Group members favoured a supportive and collaborative role whereby they could impart expert knowledge, help set the research agenda, and have 'the opportunity to correct misrepresentations and influence the direction of the research' (Kitchen 2000: 38) without taking on the responsibility or accountability of being a partner. Crucially, the RAG had a fundamental role in designing the multi-method and multi-format methodology which underpins much of this article.

\section{'Doing' reflexivity and emotional work}

1.4 While it may already be relatively transparent the extent to which the research and its epistemological, ontological and political underpinnings were embedded in my disabled identity and subjectivity (and, unexpectedly to me, my embodied experiences of disablism and ableism), in the remainder of this article I delve deeper into the processes, politics, problems, practicalities and pleasures of co-constructing disabled people's sexual stories. In doing so, I offer a reflexive but critical account. I seek to 'demystify the research activity' (Barton 2005: 319), a practice central to feminist and disability research methodologies whereby 'strong reflexivity' (McCorkel \& Myers 2003: 203) 'attends to the diversity of informants and explicates the ways that differences between researchers and respondents shape research processes' (Rice 2009: 246; see also Goodley 1999; Haraway 1988; Reinharz 1992). Importantly, this article is neither narcissistic nor self-indulgent 'vanity reflexivity' (Kenway \& McLeod 2004: 527), but seeks to take the legitimate stance of Bourdieu's reflexive sociology which calls 'less for intellectual introspection than for permanent sociological analysis and control of sociological practice' (Bourdieu \& Wacquant 1992: 40). Thus, I stay mindful of Bourdieu's suggested three main reflexive concerns: 'my personal identity'; my location within the field [2]; and my 'scholastic fallacy', the acknowledgement that my interpretation of the social world as an (intellectual) researcher is produced through the '"collective unconscious" of an academic field' (Kenway \& McLeod 2004: 529). My reflexivity in this article, then, is purposeful, and seeks to make important epistemological, ontological, and methodological contributions.

1.5 To embody these aims, I write chronologically through the research process, detailing the significant political, ethical, material, emotional, and methodological dilemmas which surrounded co-constructing the stories that disabled informants told about their (sexual) lives. Integral to this discussion are my explorations of the ways in which my identity, subjectivity and embodiment as a white, British, young, heterosexual, disabled, cisgendered woman with congenital and (often, but not always) visible impairment were interwoven within the research process and informants' sexual storytelling. Rather than occupying an 'objective, disembodied voice, without any particular vantage point or value' (Rice 2009: 249), as proclaimed in traditional positivist social research (Rice 2009), I critically consider the role of my inner and outer (embodied) self, applying a self-conscious and self-reflexive lens to the research process and beyond.

1.6 Further, as Dickson-Smith et al. (2009: 61) suggest, 'undertaking qualitative research is an embodied experience and that researchers may be emotionally affected by the work that they do' (see also Woodby et al. 2011; Davidson 2011). Thus later, I (tentatively) turn the focus towards my own (emotional) experiences of carrying out research of this kind in my bid to show 'the real story behind the finished product' (Bennet deMarrais 1998: xi). Such a focus on the 'embodied work' of researchers undoubtedly flows from sociology of work theorising on the emotional labours of employees. To clarify, 'emotional work' and 'emotional labour' are terms coined by Arlie Hochschild (1983: 7) to represent the 'labour [which] one is required to induce or suppress feeling in order to sustain the outward countenance that produces the proper state of mind to others' within the labour market. Thus, such explorations have predominantly taken place through empirical work on occupations which require 'customer interactions' such as call centres (Korczynski 2003), flight attendants (Hochschild 1983), nursing (Henderson 2001), beauty therapy (Sharma \& Black 2001) and university lecturers (Ogbonna \& Harris 2004). Utilising Exley and Letherby's (2001: 115) definition of emotional work as the 'effort and skill required to deal with one's own feelings', I examine the ways in which my own lived and embodied experiences, relationships with the RAG and informants, as well as the process more broadly, built into the emotional work required of me as a (novice) researcher. I do this not only because my 'emotional work' (Hochschild 1983) was both intensive and extensive, but because the emotional work of researchers is seldom theoretically or empirically investigated (Dickson-Smith et al. 2009; Carroll 2012; Woodby et al. 2011).

1.7 Next, I briefly reflect upon the politics of (re)telling disabled people's sexual stories - my new positionality - as I embark on a postdoctoral project ${ }^{[3]}$ to ethically, effectively, and accessibly disseminate findings from the study (outside of the academy) to disabled people, their communities, allies, and organizations. Disabled people have long been misrepresented by research and thus these politics remain a recurrent concern (Kitchin 2000). Therefore, in this section, I articulate some initial concerns. Lastly, I conclude this article by considering the important contributions which can be drawn 


\section{Co-constructing sexual stories: a dialogical process}

2.1 While multiple standard ethical guidelines were adhered to throughout the research process ${ }^{[4]}$, the act of collecting disabled people's sexual stories for the purposes of research couldn't be detached from the ways in which their lives and bodies are routinely objectified, harmed and denied privacy through oppressive social and cultural practices (Sandahl 2003). Research 'on' disabled people has been labeled 'voyeuristic', and such critiques are, rather misguidedly, aimed only at non-disabled researchers (see Bury 2001). Shakespeare (1997: 177-178) highlights how researching disabled people's sexual lives offers the potential for such narratives to be used and abused by 'unscrupulous readers [who] might find the description of disabled sex titillating'. He asserts that while it is important 'to capture the creativity and energy of disabled people's sexual expression' - omitted within much disability and sexuality research (Shuttleworth 2010; Tepper 2000) - that 'doing so runs the risk of supplying non-disabled voyeurs with material for erotic fantasies (not a usual danger of academic writing)' (Shakespeare 1997: 177-178). For me, there was a very real tension between eliciting the required data by enabling disabled people to speak about their sexual lives, and subjecting their lived experiences to a lack of privacy experienced throughout public and private life; thus serving to objectify their sexual selves and desires. Consequently, the path to analysis (and beyond) was a bumpy one, usually lined with political, ethical, material, emotional, and methodological concerns. In this section of the article, I explicate these concerns, also revealing where and how my identity, embodiment and subjectivity were intertwined with the stories people told about their lives.

\section{Sexual stories: material misgivings}

'The researcher's body can be understood as both access and limitation to the acquisition of knowledge' (Engelsrud 2005: 281).

2.2 Although not identifying as a disabled person to informants during the research process was not an option due to the visible nature of my impairment, (attempting to 'pass' would also have been contrary to my personal disability politics), my body was undeniably an asset to the acquisition of knowledge (Engelsrud 2005). In hindsight, it's clear to me now that both my disabled identity and material and physical embodiment of impairment were ever-present within the research context (Reich 2003); from accessing and recruiting informants, to the stories they told about their lives. In short these aspects of my outer self facilitated access to informants in a number of different ways. I utilised my existing network of disabled colleagues, activists, friends, and their groups and organisations to access fruitful spaces in order to recruit informants. I allowed a story of 'young-disabled-girl-done-good' to be written about me for a national charity magazine in order to get publicity for my research and put a nationwide call out for informants. I was (purposefully) transparent when identifying as disabled (including naming my impairment) on all advertising and informational literature sent to prospective informants. One organisation which distributed my call for informants to its members even requested that I make my disability (and impairment) status more explicit on advertising literature for fear that it would get a negative reaction from its members who are regularly 'called upon' by non-disabled researchers - thus reflecting the politically contentious history within disability research of non-disabled researchers conducting research on disabled people (Goodley \& Tregaskis 2005; Stone \& Priestly 1996; see also Branfield 1998).

2.3 While 'impairment does not automatically give someone an affinity with disabled people' (Barnes 1992: 121), prospective informants may have assumed that, as a fellow disabled person with lived experience of impairment and a subjective 'knowing' of being disabled, I had a more embodied understanding of the issues faced or shared their experiences. Or, that I was more trustworthy, ethical, or aligned to disability politics than other professionals in their lives. Johnson-Bailey (1999) speaks of similar fears as a black woman interviewing other black women. She states, 'there were instances where the Black women being interviewed assumed that the interviewer's status as a Black and a woman assured not only understanding but also empathy on race and gender issues' (Johnson-Bailey 1999: 659). Additionally, it's quite likely that my disabled identity and feminine subjectivity fruitfully eclipsed my 'researcher persona' in this phase of the research, a role of which most people are 'probably already wary' (Bury 1996: 111). Markedly, many informants openly stated at the beginning of their participation that they would not have taken part in the research at all, or be prepared to share as much, had I identified as, or 'been', non-disabled.

2.4 The influence of my identity and embodiment in this 'phase' of the research process, then, explicitly reveals the power of occupying a disabled identity in disability research. As Goodley and Tregaskis (2005: 367) suggest, my disabled identity and material embodiment offer a 'privileged position within disability research'. Occupying this privileged position not only bears ethical consideration when recruiting prospective informants, it - in part - comprises my ability to avoid affecting the traditional power imbalances within the researcher/researched relationship. This is because my researcher influence over informants' participation (and, more broadly, their storytelling) is - quite literally - inscribed in, on, and through my material embodiment. Rice (2009) explores similar ethical concerns as a normativelysized culturally attractive woman researching diversely embodied women's lives. She asks, 'when studying sensitive subject matters such as body image where issues of appearance cannot be overlooked, how do we account for the influence of our physicalities?' (Rice 2009: 246). Further, occupying this privileged position in disability research potentially ghettoizes the enquiry of non-disabled researchers whose unimpaired bodies can mark them as 'outsider' within the discipline; and more importantly, within the communities they research (Goodley \& Tregaskis 2005). 
mark my life could be problematic. The term 'Muscular Dystrophy' refers to a wide variety of conditions which are (mostly, though not always) characterised by a degeneration of muscle in the body over time. The substantial heterogeneity of the condition is often misunderstood through its popularised cultural understanding as 'severe', 'muscle-wasting' and 'life-threatening' (although, I don't deny for some, it is each of these). My 'type' is identified in medical circles as 'mild' and, so far, relatively static. Thus, some informants, particularly those with 'severe' or 'progressed' forms of muscular dystrophy and other neuromuscular conditions, sometimes assumed prior to meeting me that I had greater impairment than in reality. On a couple of occasions, this instigated noticeably awkward introductions when it was apparent that informants had anticipated that I would be 'more disabled'. Therefore, the reality of my material embodiment could potentially disrupt, as much as ensure, informants' participation in the research.

\section{Sexual stories: materialising methodology}

2.6 Conversely, it is the materiality of my impaired body - a body which routinely experiences restricted mobility, fatigue and pain - combined with my deep frustrations of living in an ableist social world which projects and thus perpetuates 'a corporeal standard' when it comes to bodies (Campbell 2009: 44), which informed the decision to facilitate data collection methods which were not only accessible, but sensitive to informants' own bodily experiences and interactions with disabling environments. A multi-method and multi-format methodology, co-designed with the RAG, enabled informants to tell their sexual stories through face to face interviews $(n=10)$, via email $(n=4)$, and via new social technologies, such as Skype $(n=2)$, instant messaging (e.g. MSN) $(n=4)$ or a combination $(n=2)\left(\right.$ total $\left.n=22 / 27^{[5]}\right)$. The remaining five informants $(n=5 / 27)$ chose to write their own stories through keeping a 'journal', often kept (privately from me) over several months. This design had both practical and political underpinnings. Practical, because it centred informants' comfort; offered choice; and ensured the research process was as accessible as possible. Political, because - as the RAG stressed - it was important to recognise the diverse ways in which (disabled) people communicate, but also because research should be designed with informants' needs and preferences at the forefront (rather than those of the researcher).

2.7 While such a design created considerable labour for me as a researcher, namely because it produced disparate 'styles' of data which could be technically complex to manage and code, essentially it enabled the surfacing of stories from those who, if only conventional research methods had been available, are unlikely to have participated. For example, storytelling via email and instant messaging enabled the participation of those who, for multiple reasons (likely fear or embarrassment), didn't feel able to speak about their sexual lives in person. Storytelling via instant messaging (e.g. MSN) and/or Skype was often chosen by informants who experienced pain, speech difficulties, and/or fatigue, or who just couldn't get to a face to face interview because of accessibility or institutional constraints. Storytelling via email was beneficial where informants didn't want to meet in person but for reasons of limited manual dexterity didn't want to be interviewed via instant messaging technology (which requires good typing skills). Storytelling via writing a journal enabled Grace ${ }^{[6]}$, a 58 year old Deaf woman who was concerned at having a British Sign Language (hereby BSL) interpreter present at a face-to-face interview (because of the impact on confidentiality) to participate, because no BSL interpreter was needed. Not surprisingly, as part of the 'Facebook generation' (Meadows-Klue 2008: 245), 'online methods' were most popular with younger informants (30 years and under) $(n=5)$. Significantly, these online methods offered a further informality which put younger informants at ease, at the same time as providing absolute anonymity, even to the researcher. Tellingly, many informants made method and format choices purely out preference (rather than for accessibility reasons), highlighting that social research methodologies generally could benefit from privileging informant preferences and comfort. This is particularly so within the researching of sensitive topics 'where research intrudes into the private sphere or delves into some deeply personal experience' (Lee and Renzetti 1993: 6).

2.8 Thus, while the utilisation of new social technologies and 'online methods' within qualitative research remains cautious, and markedly in the shadows of the face-to-face encounter which remains the 'the quintessence of qualitative research' (Seymour 2001: 155), such data collection methods are, I suggest, of significant value to existing and emerging disability research methodologies. Firstly, because they are malleable to a multitude of different bodies, embodiment, and bodily capabilities (Seymour 2001). Secondly, because online spaces can offer greater accessibility and privacy; and thirdly, new social technologies can provide a means of disabled people participating in research without this becoming known to personal assistants, carers, partners and parents. This was particularly pertinent within this study, given that lacking privacy - an often-routine experience for people with impairment - was at the heart of many informants' sexual stories. Specifically, because 'disabled people face a considerable amount of curiosity and voyeurism' (Shakespeare 1996: 66) combined with 'a lack of sexual privacy' (Siebers 2008: 138).

\section{Sexual stories: telling and identity}

'Interviewing is rather like a marriage: everybody knows what it is, an awful lot of people do it, and yet behind each closed door there is a world of secrets.' (Oakley 1981: 41)

2.9 Nowhere were my identity, subjectivity and embodiment more important in the dialogical process of sexual storytelling than in my role as an interlocutor and co-constructor of informants' stories. Importantly, my age, socio-economic background, gender, sexual orientation, whiteness, and disability were determining factors which influenced the power dynamics of the researcher/researched relationship and thus contoured the ways in which stories were told - often quite literally. For example, older informants (I was just 24 when the research commenced) could be very 'protective' of me (despite my traditional authority and privilege as the researcher), initially shielding me from 'rude' words and sexually explicit 
details in the telling of their stories (this was likely further compounded by my gender). Another older informant said that he initially felt very uncomfortable talking about sex to a woman 'his daughter's age'. In this case, I affirmed his existing feelings of inappropriateness surrounding his sexuality, a common psycho-emotional impact of disabled people's cultural desexualisation (Reeve 2002). Another informant, Bob, an older man with physical and sensory impairment, switched from telling his story in person to via email (after arranging and cancelling two meetings) because, he said, meeting me in a public place would have meant reliving bad memories whereby he had arranged to meet prospective partners who had either not turned up or left after seeing him. Therefore, even an informant's choice of storytelling medium could rest precariously at the intersections of (most clearly) my gender and sexual identities.

\section{Troubling whiteness}

2.10 Song and Parker (1995: 24) assert, 'where two people may claim commonality on one dimension, they may fall apart on another'. Thus, I found that the shared experiences of disability, impairment and ableism I had with certain informants could, at points, be interrupted by cross race positionality. While I was conscious of black feminist and womanist critiques of white feminist scholarship (see bell hooks 1981), and had made concerted efforts to attract a diverse sample (particularly along the lines of sexual orientation and race), I had not critically considered the ways in which my ethnic origin might impact upon the research process and informants' sexual storytelling. Thus, the invisibility of my whiteness to meindistinctness undoubtedly afforded to me by my white privilege - meant that I seldom interrogated and problematised my racial identity to the same extent as other facets of my identity. As uncomfortable as it is now to admit, my whiteness (and, surprisingly, my 'Britishness') only became clearly apparent to me upon hearing the sexual stories of informants from ethnic minority groups $\left(n=4 / 26\right.$, all men $\left.{ }^{[7]}\right)$, whose stories of sexual oppression were frequently further layered by their cultural, religious, and racial identities.

2.11 Further, I was taken aback by the extent to which my whiteness had informed my then-knowledges of disability and sexuality. Hearing these informant's stories, which were distinctly told around their racial and cultural identities in a way not visible (at least to me at that time) in the stories of white informants, enabled me to ruminate cross-culturally and consider the role of the family, tradition, community, and faith in the making of disabled sexualities. In hindsight, more could have been done to recruit informants from ethnic minority groups; particularly ethnic minority women, whose experiences of gender would have provided an interesting comparison to other women in the sample, all of whom were white (see Egharevba 2001). Thus, my social, cultural and scholarly knowledges of disability rested not only upon my own embodied whiteness, but were inevitably exacerbated by the stark whiteness of disability studies as a discipline (Bell 2010). My insufficient knowledge of the complex intersections of race, sexuality and disability, then, are imprinted upon these informant's stories and, as some Black feminists have argued (see Hill-Collins 2000), this cross race positionality vis-à-vis these research subjects has produced certain kinds of knowledge. This strongly affirms the necessity of self-reflexivity towards negating the potential ethnocentrism and (unconscious) racism within white feminist and disability research (Reinharz 1992).

\section{Troubling gender, heterosexuality and intimacy}

2.12 Moving on, it was not uncommon that the interview setting was the first space in which some informants had ever talked about issues such as sex and love with another person. Many had been ridiculed, humiliated or chastised when raising such topics within their own familial and social networks (Shakespeare et al. 1996). This inevitably brought significant responsibility when managing informants' participation in a way which would not quash the confidence it took for them to participate. The intimate nature of the research topic combined with the sense of speaking about sex and love without fear or judgment created some strong researcher/researched relationships. In addition, the extensive work it took to ensure informants made it to participation (for example, regular conversations about access, informants outlining their life stories in order to determine 'eligibility', and the regular reassurance and contact required) meant that these relationships could already be developed prior to participation. This suggests, then, that in the researching of sensitive topics, it is likely that relationships between researcher and researched may become intimate prior to an informant's actual participation in the research. At times, such relationships became ethically complex to manage. For example, in order to protect informants I had to maintain a 'professional distance' (Fetterman 1991: 94) while at the same time constructing a supportive environment conducive to eliciting intimate experiences. This could be further complicated for informants who experienced considerable social isolation in their lives. For example, a few informants became very dependent on the research relationship as a means of contact with another person. This highlighted the ethical circumstances of facilitating this relationship (for the elicitation of data), and more importantly, how to end it without causing considerable harm. Upon ending the research relationship with these informants, I remained in 'light contact' for a while following their participation - which came to an organic end - rather than simply ending the researcher/researched relationship abruptly.

2.13 Undeniably, my heterosexual identity could further complicate this process (see Poulton 2012). Drawing upon her research with divorced fathers. Arundell (1997: 364-365) found 'that the norms of the situation of the research interview did not override or displace those of a gender stratified society; gender work was ever present and predominant'. Similarly, some male informants seldom abstained from performing typical heterosexual scripts, and thus keenly reaffirmed 'the conventional gender hierarchy as they told about their experiences' (Arundell 1997: 364). Some male informants could confuse the open, supportive and gentle context of the interview and pre and post-participation contact with romantic or sexual feelings. Some men openly flirted throughout the interview (possibly enacting a sexualised and gendered identity they couldn't perform elsewhere). While sometimes this was in the context of asking questions about my own sexuality or sexual life, other times it was far more overt. Four male informants 
$(n=4 / 16)$ asked to meet again in a social/sexual context following participation which created a predicament whereby I had to decline such an offer without affecting their self-esteem or affirming their experiences of rejection, which were often central to their stories.

2.14 At other times, a few informants (who were later excluded), could be sexually objectifying and sometimes frightening through exhibiting inappropriate behaviour before, during, and after participation (see Peng 2007; Sanders 2008). As a young, female researcher embarking on her first piece of 'proper' research, this was very upsetting. Not least in its immediacy, but also because it served as a stark reminder of the objectifying sexism which plagues women's lives, even within professional contexts (Pierce 1995; Poulton 2012). Other feminist scholars have reflected on the sexism and objectification they've experienced in the field, revealing how sexism is often part and parcel of doing research as a woman interviewer/ethnographer (Kang 2010; Pierce 1995). In these moments, when men: sent constant texts to my research phone number offering me sex; insisted I needed 'a good fuck'; or left me lewd voicemails messages, I was reduced to a sexual object. My worst experience was with a male informant - who was withdrawn following interview - whom I felt 'duped me', with me setting up, paying for, and travelling 150 miles to the agreed venue under the guise that he had a sexual story to tell. In reality, the meaning of the interview to him was merely an opportunity to speak about his (what I deem) abusive, exploitative and violent acts with sex workers, simultaneously getting aroused at the same time and violating my bodily boundaries (see Sanders 2008).

2.15 Thus far, I've critically explored the impact of my intersectional identity and lived experiences upon the research process, data collection and my relationships with informants. In the subsequent section of the article I (tentatively) turn my focus to consider the impact of these aspects of the research process upon me (Bennet deMarrais 1998: xi). I account, then, for the personal behind the (research) politics, exploring the considerable emotional work and management (Hochschild 1983) required of qualitative researchers. This, I suggest, is most acute when informants' lived experiences of oppression intersect with your own.

\title{
The emotional work of hearing stories
}

\section{Hard work}

3.1 Listening to the stories of others, through which tales of isolation, loneliness, self-hatred, and abuse were not uncommon, was often gruelling (see Klienman \& Copp 1993). Many of the stories told were ones of pride, self-confidence, resistance, and personal strength. Others embodied the oppression, discrimination, and prejudice many disabled people face as part of their daily lives. Importantly, my own biography and subjectivity were complicit in my emotional work, as my own lived experiences were repeatedly echoed in the stories of others (Davidson 2011). At points, hearing informants' stories caused the surfacing of irrational fears:

\begin{abstract}
Hearing Julie's sad story of her husband rejecting her at the onset of her impairment because he 'didn't want a disabled wife' was very disturbing. She hid nothing from me and it upset me greatly. Later that evening at home I broke down to my partner, part through relief that the day was over, but more out of insecurity that he could leave me in much the same way. Julie reported a strong relationship, a great man who loved her very much, yet I had all of these things... I was firing such accusations at my partner with incredible speed, What makes us so different?'... Realistically and logically, I don't think that will ever be my life. I genuinely believe in, and have more faith in my partner than that, but when it's emotively in front of you all day it's impossible not to be affected by it.

It was at this juncture that I suddenly realised that my research could be harmful. Not just for those whose stories I hoped to hear, but harmful to me, my sense of self, my relationships, and those around me. As I heard Julie's words I realised that she was voicing my worst

fears. I may find elements of stories that remind me of my worst fears, or echo my feelings about myself and my body on the darkest days... How will I deal with this?

(Research Diary $4^{\text {th }}$ June 2009)
\end{abstract}

The above account was written in my research diary following a particularly bad day 'in the field' after which, as Davidson (2011: 5.12) aptly states, 'I wanted to cocoon myself for days'. My words here are indicative of the impact of hearing certain stories, but more importantly show how my own lived and embodied experiences are built into my emotional working. Thus, such fears were also rational, in that they were underpinned by my shared identities and marginalities with informants. Significantly, this emotional work was not only realised upon hearing stories, but served as an unceasing anxiety which could resurface at particular times throughout the research process; for example, when transcribing interviews and coding and analysing informants' narratives. This was likely because these activities involved a more convoluted and exhaustive engagement with individual stories. Further, this emotional engagement was compounded by the very nature of doctoral study: inquiry carried out primarily alone (rather than as part of a research team), by novice researchers who are 'particularly vulnerable to the emotional challenges' (Woodby et al. 2011: 830), and who have little awareness of the self-care practices which may reduce researcher distress when researching sensitive topics (Woodby et al. 2011). In this instance, keeping a research diary was a self-discovered self-care strategy implemented promptly upon encountering the above emotions in the field.

3.2 Another form of considerable emotional work was in managing the sexist, disablist, and racist language and beliefs voiced by some informants. Due to the need to elicit data, these were prejudices to which I could neither react nor object. Thus, at these points I had to perform a presentation of my self as a professional researcher (see Poulton 2012). For example, it was troublesome to hear some disabled 
men's opinions on disabled and/or fat women, who were routinely positioned as objects of disgust (affirming the cultural messages which are readily ascribed to my impaired female bodily aesthetic). Similarly, disabled male informants who had paid for sex often constructed sex workers in very particular ways when telling their stories. For example, many were sizeist, dehumanising ('it was a choice of two, a Polish or an English'), racist, deeply sexist and placed these women's bodies and behaviours under significant scrutiny. These moments made for some difficult listening and revealed, in very raw ways, the problematic tensions which subsist between my liberal feminist and disability politics (see Lloyd 2001; O'Connell-Davidson 1998; Sanders 2008). To clarify, I accept sex work as both a form of embodied labour for sex workers (see Boris et al. 2010) and as a legitimate means of sexual access for disabled people (Sanders 2008). However, the act of (mentally and emotionally) negotiating the rights, perspectives, and politics of both of these marginalised groups (see Wotton \& Isbister 2010) explicitly at the juncture of hearing men's sex work stories could be a conflicting task which, at points, required considerable effort to remain sympathetic to disabled men's plights.

3.3 However, possibly the most distressing aspect of listening to stories was hearing the extent of informants' internalised oppression and experiencing of psycho-emotional disablism (Reeve 2002), defined by Thomas (1999: 60) as 'the socially engendered undermining of emotional well-being'. For example, some informants (and a research advisory group member) expressed that, although they respected my efforts, politicising disabled people's oppression was meaningless because disability is a biological, natural and genetic inferiority of which social oppression is both justified and inherent to human nature (see Campbell 2009). Beyond internalised oppressions, it was also difficult to hear about the sexual, emotional, and physical violence which featured in informants' stories with striking frequency. Another struggle, was acknowledging both the silence around and negative experiences within motherhood for many disabled women in the research (see Kent 2002; O'Toole 2002). Just three of the nine disabled women who participated were mothers, and each of these women told stories of the discrimination and prejudice to which they were subjected by strangers, medical professionals, family planning clinics, and friends and family members within their mothering experiences. Female informants without children either quickly changed the subject when the topic of motherhood arose, or categorically stated that their experiences of both impairment and disability heavily contributed to their decision not to become mothers (see Thomas 1997). As a disabled woman (who wants to be a mother), hearing the impact of such experiences led to considerable emotional distress; not least because such stories embodied the notion that motherhood remains an area of social life through which disabled women are at best excluded and at worst abused (Prilleltensky 2003).

\section{Providing emotional support? The role of the RAG}

3.4 In addition to keeping a research diary, another self-care strategy emerged from my engagement with the RAG. Even prior to the commencement of any field work, the group's laughter, support, guidance and enthusiasm fostered a relaxed space through which I learned to speak to fellow disabled people about sex and intimacy. In particular, some RAG members warmly shared their own stories as a prerequisite to designing how the stories of others could be collected and used. Thus, I was actively taught to listen (see Barton 2005). The RAG enabled a safe space through which I 'practiced' asking questions and where I was (often brutally and crudely, but with much laughter) taught the intricacies of impairment and sexual practice and pleasure (for example, knowing about medications, medical equipment, personal assistants/care, and bodily processes such as incontinence etc.). This knowledge was fundamental towards learning how to enquire about the materialities and realities of sexuality and impairment. Such access to expert and lived knowledge was the major benefit of establishing and maintaining the RAG. In fact, there were few drawbacks to the group: there was no contention amongst group members; once the group was established, it took little 'extra' work; and it enabled a solid, rather than tokenistic, participatory process to take place (Barton 2005). Further, having to 'report' to the RAG (while sometimes stressful) was not only impetus to keep the research process constantly moving forward at a time when I just wanted to give up, but served as a way to habitually keep reflecting upon each stage of the process. Crucially, the RAG kept the research grounded in the everyday realities of disabled people's lives. Questions asked by group members within meetings disrupted much of my intellectual and theoretical romanticism and idealism; for example, questions such as 'What difference does that make?' and 'So what?'enabled me to keep the (political) purpose of the research in view.

3.5 However, while my relationships with group members (and theirs to one another) were warm, they were ultimately professional. Thus, I seldom utilised the RAG explicitly for emotional support, for a number of reasons. Firstly, I didn't want to disrupt the good will of the group, or make unreasonable demands in terms of individual group members' time and engagement with the process. Secondly, I didn't feel group members were emotionally close enough to me to aid disclosure; and lastly, because I was conscious I had to be the competent and capable (researcher) 'glue' which held the group (and the broader process) together. Thus, ultimately, I felt that disclosing my emotional distress would compromise this professional performance (see Woodby et al. 2011), and instead chose to 'mask it' via enacting the 'appropriate' 'display work' central to Hochschild's $(1983,10)$ emotional labour.

\section{Pleasurable work}

3.6 While I have documented the negative, painful, or exhaustive emotional work of the research process, as other empirical investigations into the emotional experiences of researchers have done (Woodby et al. 2011; Carroll 2012), my emotional investment with informants' storied lives was sometimes pleasurable (see Davidson 2011). For some informants, taking part in the research and 'speaking out' about their experiences was part of a wider narrative of emancipation in other areas of their lives. Thus, their participation was underpinned by significant and poignant personal motivations and could be a catalyst for other changes in their lives. For example, Lucille, a married 36 year old woman with an acquired spinal 
injury, experienced writing her sexual story as a cathartic activity which allowed her to explore fragments of her life she had 'shut down' after injury. On our last contact, she told me that telling her story had empowered her in ways she hadn't imagined possible; for example, she'd worn a skirt for the first time since her accident (10 years previous) because she 'finally felt comfortable as a disabled woman'. Lucille's journey to self-acceptance as a proud disabled woman, which I saw emotively unfold throughout her journal, empowered me considerably. As a young disabled woman I've seldom had access to strong and visible disabled female role models (other than disabled feminist scholars) (see Gillespie-Sells et al. 1998). Therefore, far from the artifice of objectivity, such stories of emancipation - which embodied the (potential) empowerment of personal narrative (Langellier 2001) - were very impactful and instigated strong emotional bonds. Had I continued contact with Lucille and other informants following their participation I've no doubt that these relationships would have grown to become strong friendships (see Zajano \& Edelsberg 1993).

\section{Moving forward... (re)telling sexual stories}

4.1 Finally, I now turn to the politics of (re)telling disabled people's sexual stories - my new positionality as I embark on a postdoctoral project to ethically, effectively, and accessibly disseminate findings from the study (outside of the academy) to disabled people, their communities, allies, and organisations. Shakespeare (1996: 117) suggests that 'disabled academics are subject to at least two monitoring processes: academic colleagues and movement comrades'. Notably, Shakespeare (1996: 117) manages to take a distinctly masculinist, 'hard line' approach suggesting that his academic perspective offers the 'chance to consider issues which may have been overlooked in the heat of political debates'. Thus, he is clear that while he supports disability movements, he is not obligated to stay loyal to them (Shakespeare 1996). I, however, don't share the same chutzpah, and remain very aware of the power of an authoritative voice (re)telling Others' stories. This is in particular reference to the ways in which representing certain types of stories may affirm oppressive ableist narratives and portrayals of disabled sexualities, rather than challenge them. For example, revealing disabled men's sex work stories could be argued to legitimate oppressive conceptualisations of disabled (male) sexualities as deviant and perverse (Brown 1994). Simultaneously, presenting the abuses disabled informants experienced throughout their intimate relationships may contribute to the harmful discourses of 'vulnerability' which plague disabled people, and which are not only disempowering, but dangerous (Waxman-Fiduccia 1991; Hollomotz 2010).

4.2 There is now, rightly, burgeoning caution of the ways in which life stories collected with the best of intentions can be harmful to the interests of marginalised and Othered communities (Costa et al. 2012). For example, Costa et al. (2012: 86) have documented the problematic ways in which the life ('recovery') stories of psychiatrised people have become powerful commodities for mental health services which bastardize such stories to 'garner support from authority figures such as politicians and philanthropists', 'to build the organizational "brand"', and 'to raise operating funds during times of economic constraint'. My aim, however, is that by undertaking the privileged position of (re)telling stories I make them more accessible, and that this (re)telling of individual and collective stories challenges the oppressive ableist silences which surround disabled people's sexual lives, bodies, and pleasures (Siebers 2008; Tepper 2000). Therefore, my voice as an interpreter does not, I hope, have the effect of disrupting, distorting, or removing stories from their subjective reality, but serves to assist disabled peoples' sexual stories in being heard and understood. More importantly, at the heart of this is a will to faithfully return stories - and my interpretation of them - to the spaces from which they were gained, with the primary intention of contributing to disabled people's emerging sexual politics and claims for sexual citizenship (Plummer 1995, 2003).

\section{Drawing some conclusions}

5.1 To sum up, then, this article has offered a reflexive account of the processes, politics, problems, practicalities and pleasures of storying disabled peoples' sexual lives for the purposes of sociological research. I have shared '"warts and all" admissions which are all too often absent from the usual research methods textbooks and "impact driven" research articles, which usually present "sanitised" accounts of methodological processes and practice' (Poulton 2012: 1.2). This reflexive practice not only proves useful for fellow postgraduate and early career researchers (who can learn from my frequent dilemmas), but uncovers a number of important contributions. Essentially, my reflections affirm feminist epistemologies which situate reflexivity, accountability and positionality as central to creating certain kinds of knowledge (Walby 2011). Thus, this article has explicitly shown the ways in which researcher identity, subjectivity, embodiment and lived experience are not merely parts of research, but instead may be the sum of it.

5.2 Undoubtedly, accounting for my many research dilemmas has revealed my complex positionality; how facets of my identity were manifest in different ways - and in distinct moments - dependent upon encounters with informant's identities (see England 1994). These moments have illuminated 'the ways that differences between researchers and respondents shape research processes' (Rice 2009: 246). Further, I have shown the ways in which multiple aspects of the research process - research design; informant recruitment; researcher/researched relationships; and data collection - were/are embedded in my identity, subjectivity and embodiment as a white, British, young, heterosexual, disabled woman with congenital impairment. Thus, I hope I have articulated fully the ways in which my inner and outer selves have strengthened the research, rather than weakened it (as is propositioned within positivistic assumptions). Thus, by examining the connections between myself and the process - or through 'demystifying the research activity' (Barton 2005: 319) - I have painted a far richer picture of researching disabled peoples' sexual lives. This richer picture not only benefits readers who may want to carry out similar research, or use similar methodologies, but (rightly and publically) holds my researcher ethics, politics and actions to account (Bennet deMarrais 1998; England 1994).

5.3 Moving forward, providing a reflexive account has enabled me to identify and (re)consider layers of 
identity privilege (my whiteness) that I had overlooked in comparison to other facets of my identity which seldom invite such privilege (my disabled identity). I suggest that this omission may be a common occurrence within disability research, and that this in turn exacerbates the marked whiteness of disability scholarship (Bell 2010); a transdisciplinary space which has only recently made a commitment towards theorising 'disability' in the Global South (Meekosha \& Soldatic 2011). Thus, for Disability Studies specifically, the act of 'doing' reflexivity offers (white) disability scholars a means through which to (re)configure an understanding of whiteness (and race and ethnicity generally) at a time of emerging intersectional and global knowledges of disability. However, as England (1994: 250) argues, while reflexivity 'can make us more aware of asymmetrical or exploitative relationships [within research], it cannot remove them'. Thus, while it is pertinent that the reflexivity of disability studies scholars betterextends to race, there is far more to be done to counter the entrenched whiteness within 'White Disability Studies' (Bell 2010: 374), highlighting, then, some very real limits of reflexivity as an epistemological practice (England 1994).

5.4 Finally, through critically exploring my own emotional engagement with the research process, I have contributed to others' calls (see Carroll 2012; Dickson-Smith et al. 2009) for the inclusion of researchers' emotions to the process. As Carroll (2012: 13) states, 'the incorporation of emotions and their analysis into theoretical study on the sociology of emotion can be crucial to extending theory'. Thus, I suggest that the emotional engagement of researchers isn't just 'there' - to be excused - but is legitimate and productive. Moreover, alongside 'doing' reflexivity, researcher emotion can become a crucial instrument 'for conducting qualitative research on emotional topics' (Carroll 2012: 13). My own embodied experiences of emotional work reveal the ways in which researcher identity, subjectivity and embodiment can contour, compound and contribute to the emotional work experienced by qualitative researchers. This is, undoubtedly, of prominence for disability and feminist scholarship where researchers and research informants are likely to occupy similar social locations, oppressions, and embodied knowledges. A further reason behind (publicly) sharing this very private and personal part of the process was to highlight the specific circumstances around novice and/or doctoral qualitative researchers, whose experiences of emotional work are potentially intensified by their relative lack of field experience. By 'speaking out' about my experiences I invite further dialogue in the hope that collectively sharing emotions, research journeys, and strategies of management and self-care may be one answer towards lessening the burden of emotional work which 'as a community, we often fail to openly discuss' (Woodby et al. 2011: 238).

\section{Notes}

${ }^{1}$ In total, 10 disabled women, 15 disabled men and 1 female non-disabled partner (who was interviewed alongside a disabled informant at their request) $(n=26)$, of different ages, ethnicities, socio-economic backgrounds, sexual orientations, and with a diversity of impairments told their sexual stories.

${ }^{2} \mathrm{My}$ 'field', as defined in this article, refers to qualitative sociology, disability studies scholarship and research, and, as an early career researcher, the Academy more broadly.

${ }^{3}$ This postdoctoral project is joint-funded by the Ethel Louise Armstrong Foundation and Ryerson University, Toronto, Canada.

${ }^{4}$ Ethical approval was granted by The University of Warwick Humanities and Social Sciences Research Ethics Committee (HSSREC). In addition, the study adhered to The British Sociological Association's (BSA) Statement of Ethical Practice and the Economic and Social Science Research Council's (ESRC) Research Ethics Framework.

5 In total, 27 sexual stories were collected, though only 26 were analysed due to one being withdrawn prior to analysis.

${ }^{6}$ All informant names used within this article are pseudonyms.

${ }^{7}$ Ethnic minority informants identified as African $(n=1)$, British-Asian $(n=1)$ and British-Indian $(n=1)$ and unknown $(n=1)$ (this informant took part in an email interview and did not reveal his ethnicity other than to state he wasn't White British).

\section{References}

ARUNDELL, T. (1997) 'Reflections on the researcher-researched relationship: a woman interviewing men', Qualitative Sociology, 20(3) p. 341-368.

BARNES, C. (1992) Disabling Imagery. Derby: BCDODP.

BARTON, L. (2005) 'Emancipatory research and disabled people: some observations and questions', Educational Review, 57(3) p. 317-327.

BELL, C. (2010) 'Is disability studies actually white disability studies?', in Davis. L (Ed.), The Disability Studies Reader. New York: Routledge.

BELL hooks (1981) Aint I a Woman: Black Women and Feminism. Cambridge, MA: Southend Press. 
BENNET DEMARRAIS, K. (1998) Inside Stories: Qualitative Research Reflections. London: Routledge.

BORIS, E., Gilmore, S. \& Parreñas, R. (2010) 'Sexual labors: interdisciplinary perspectives toward sex as work', Sexualities, 13(2) p. 131-137.

BOURDIEU, P. \& Wacquant, L. (1992) An Invitation to Reflexive Sociology. Chicago: University of Chicago Press.

BRANFIELD, F. (1998) 'What are you doing here? Non-disabled people and the disability movement: a response to Robert F. Drake', Disability and Society, 13(1) p. 143-144.

BROWN, H. (1994) 'An ordinary sexual life? A review of the normalisation principle as it applies to the sexual options of people with learning disabilities', Disability and Society, 9(2) p. 123-144.

BURY, M. (1996) 'Defining and researching disability: challenges and responses', in Barnes, C. \& Mercer, G. (Eds.), Exploring the Divide: Illness and Disability, Leeds: The Disability Press.

CAMPBELL, F. (2009) Contours of Ableism: Territories, Objects, Disability and Desire. London: Palgrave Macmillan.

CARROLL, K. (2012) 'Infertile? The emotional labour of sensitive and feminist research methodologies', Qualitative Research, 12 p. 1-16.

CHAUNCEY, G. (1995) Gay New York: Gender, Urban Culture, and the Making of the Gay Male World, 1890-1940. New York: Basic Books.

COSTA, L., Voronka, J., Landry, D., Reid, J., McFarlane, B., Reville, D. \& Church, K. (2012) 'Recovering our stories: a small act of resistance', Studies in Social Justice, 6 p. 85-101.

DAVIDSON, D. (2011) 'Reflections on doing feminist research grounded in my experience of perinatal loss: from auto/biography to autoethnography', Sociological Research Online, 16(1) article 6 <http://www.socresonline.org.uk/16/1/6.html>

DAVIES, D. (2000) 'Sharing our stories, empowering our lives: don't dis me!', Sexuality and Disability, 18 p. $179-186$

DEI, G. S. \& Johal, G. S. (2005) Critical Issues in Anti-Racist Research Methodologies. New York: Lang.

DICKSON-SMITH, V., James, E. L., Kippen, S. \& Liamputtong, P. (2009) 'Researching sensitive topics: qualitative research as emotion work', Qualitative Research, 9(1) p. 61-79.

EGHAREVBA, I. (2001) 'Researching an-"other" minority ethnic community: reflections of a black female researcher on the intersections of race, gender and other power positions on the research process', International Journal Social Research Methodology, 4(3) p. 225-241.

ENGELSRUD, G. (2005) 'The lived body as experience and perspective: methodological challenges', Qualitative Research, 5(3) p. 267-284.

ENGLAND, K. V. L. (1994) 'Getting personal: reflexivity, positionality, and feminist research', The Professional Geographer, 46(1) p. 80-89.

EXLEY, C. \& Letherby, G. (2001) 'Managing a disrupted life course: issues of identity and emotion work', Health, 5(1) p. 112-132.

FETTERMAN, D. (1991) Using Qualitative Methods in Institutional Research. San Francisco: Jossey-Bass.

GILLESPIE-SELLS, K., Hill, M. \& Robbins, B. (1998) She Dances to Different Drums. London: King's Fund.

GOODLEY, D. (1999) 'Disability research and the "researcher template": reflections on grounded subjectivity in ethnographic research', Qualitative Research, 5(1) p. 24-46.

GOODLEY, D. \& Tregaskis, C. (2005) 'Storying disability and impairment: retrospective accounts of disabled family life', Qualitative Health Research, 16(5) p. 630-646.

HARAWAY, D. (1988) 'Situated knowledges: the science question in feminism and the privilege of partial perspective', Feminist Studies, 14(3) p. 575-599.

HENDERSON, A. (2001) 'Emotional labour and nursing: an under-appreciated aspect of caring work', Nursing Inquiry, 8(2) p. 130-138.

HILL-COLLINS, P. (2000) Black Feminist Thought: Knowledge, Consciousness, and the Politics of Empowerment (2nd ed.). New York and London: Routledge.

HOCHSCHILD, A. (1983) The Managed Heart: Commercialization of Human Feeling. Berkeley, Los Angeles, London: University of California Press. 
HOLLOMOTZ, A. (2010) 'Sexual "vulnerability" of people with learning difficulties: a self-fulfilling prophecy', in Shuttleworth, R. \& Sanders, T. (Eds.), Sex and Disability: Politics, Identity, and Access. Leeds: The Disability Press.

JOHNSON-BAILEY, J. (1999) 'The ties that bind and the shackles that separate: race, gender, class, and color in a research process', Qualitative Sociology, 12(6) p. 659-670.

KANG, M. (2010) The Managed Hand: Race, Gender, and the Body in Beauty Service Work. USA: University of California Press.

KENNEDY, E. L. \& Davis, M. D. (1993) Boots of Leather, Slippers of Gold: The History of a Lesbian Community. New York: Routledge.

KENT, D. (2002) 'Beyond expectations: being blind and becoming a mother', Sexuality and Disability, 20(1) p. 81-88.

KENWAY, J. \& McLeod, J. (2004) 'Bourdieu's reflexive sociology and "spaces of points of view": whose reflexivity, which perspective?', British Journal of Sociology of Education, 25(4) p. 525-544.

KITCHEN, R. (2000) 'The researched opinions on research: disabled people and disability research', Disability and Society, 15(1) p. 25-47.

KITCHIN, R. (2001) 'Using participatory action research approaches in geographical studies of disability: Some reflections', Disability Studies Quarterly, 24(4) p. 61-69.

KORCZYNSKI, M. (2003) 'Communities of coping: collective emotional labour in service work', Organization, 10(1) p. 55-79.

LANGELLIER, K. (2001) '"You're marked": breast cancer, tattoo and the narrative performance of identity', in Brockmeier, J. \& Carbaugh, D. (Eds.), Narrative and Identity: Studies in Autobiography, Self, and Culture. Amsterdam and Philadelphia: John Benjamins.

LEE, R. \& Renzetti, C. (1993) Researching Sensitive Topics. London: Sage Publications.

LLOYD, M. (2001) 'The politics of disability and feminism: discord or synthesis?', Sociology, 35(3) p. 715728.

MCCORKEL, J. \& Myers, K. (2003) 'What difference does difference make? Position and privilege in the field', Qualitative Sociology, 26(2) p. 199-231.

MEADOWS-KLUE, D. (2008) 'Opinion piece: Falling in Love 2.0: relationship marketing for the Facebook generation', Journal of Direct, Data and Digital Marketing Practice, 9 p. 245-250.

MEEKOSHA, H. \& Soldatic, K. (2011) 'Human rights and the global south: the case of disability', Third World Quarterly, 32(8) p. 1383-1397.

O'CONNELL-DAVIDSON, J. (1998) Prostitution, Power and Freedom. Cambridge: Polity.

O'TOOLE, Corbett J. (2002) 'Sex, disability and motherhood: access to sexuality for disabled mothers', Disability Studies Quarterly, 22(4) p. 87-108.

OAKLEY, A. (1981) 'Interviewing women: a contradiction in terms', in Roberts, H. (Ed.), Doing Feminist Research. London: Routledge and Kegan Paul.

OGBONNA, E. \& Harris, L. C. (2004) 'Work intensification and emotional labour among UK university lecturers: an exploratory study', Organization Studies, 25(7) p. 1185-1203.

OLIVER, M. (1992) 'Changing the social relations of research production', Disability and Society, 11(2) p. $115-120$.

PENG, Y. W. (2007) 'Buying sex. Domination and difference in the discourses of Taiwanese piao-ke', Men and Masculinities, 9(3) p. 315-336.

PIERCE, J. L. (1995) Gender Trials: Emotional Lives in Contemporary Law Firms. USA: University of California Press.

POULTON, E. (2012) '"If you had balls, you'd be one of us!" Doing gendered research: methodological reflections on being a female academic researcher in the hyper-masculine subculture of "football hooliganism"', Sociological Research Online, 17(4) article $4<\mathrm{http}: / /$ www. socresonline.org.uk/17/4/4.html>

PLUMMER, K. (1995) Telling Sexual Stories: Power, Change and Social Worlds. London: Routledge.

PLUMMER, K. (2003) Intimate Citizenship: Private Decision and Public Dialogues. Seattle and London: University of Washington Press.

POLE, C. \& Lampard, R. (2002) Practical Social Investigation: Qualitative and Quantitative Methods in Social Research. Essex: Pearson Education Ltd. 
PRILLELTENSKY, O. (2003) 'A ramp to motherhood: the experiences of mothers with physical disabilities', Sexuality and Disability, 21(1) p. 21-47.

REEVE, D. (2002) 'Negotiating psycho-emotional dimensions of disability and their influence on identity constructions', Disability and Society, 17(5) p. 493-508.

REICH, J. (2003) 'Pregnant with possibility: reflections on embodiment, access, and inclusion in field research', Qualitative Sociology, 26(3) p. 351-367.

REINHARZ, S. (1992) Feminist Methods in Social Research. USA: Oxford University Press.

REMBIS, M. (2010) 'Beyond the binary: rethinking the social model of disabled sexuality', Sexuality and Disability, 28 p. 51-60.

RICE, C. (2009) 'Imagining the other? Ethical challenges of researching and writing women's embodied lives', Feminism and Psychology, 19(2) p. 245-266.

SANDAHL, C. (2003) 'Queering the crip or cripping the queer? Intersections of queer and crip identities in solo autobiographical performance', GLQ: A Journal of Lesbian and Gay Studies, 9(1) p. 25-56.

SANDERS, T. (2008) Paying for Pleasure: Men Who Buy Sex. USA and Cullompton: Willan Publishing.

SCHILT, K. (2011) Just One of the Guys?: Transgender Men and the Persistence of Gender Inequality. Chicago: University of Chicago Press.

SEYMOUR, W. S. (2001) 'In the flesh or online? Exploring qualitative research methodologies', Qualitative Research, 1(2) p. 147-168.

SHAKESPEARE, T. (1996) 'Power and Prejudice: issues of gender, sexuality and disability', in Barton, L. (Ed.), Disability and Society: Emerging Issues and Insights. Harlow: Longman.

SHAKESPEARE, T. (1997) 'Researching disabled sexuality', in Barnes, C. \& Mercer, G. (Eds.), Doing Disability Research. Leeds: The Disability Press.

SHAKESPEARE, T., Gillespie-Sells, K., and Davies, D. (1996) Untold Desires: The Sexual Politics of Disability. London and New York: Cassell.

SHARMA, U. \& Black, P. (2001) 'Look good, feel better: beauty therapy as emotional labour', Sociology, 35(4) p. 913-931.

SHUTTLEWORTH, R. (2010) 'Towards an inclusive disability and sexuality research agenda', in Shuttleworth, R. \& Sanders, T. (Eds.), Sex and Disability: Politics, Identity, and Access. Leeds: The Disability Press.

SIEBERS, T. (2008) Disability Theory. USA: University of Michigan Press.

SONG, M. \& Parker, D. (1995) 'Commonality, difference and the dynamics of discourse in in-depth interviewing', Sociology, 29(2) p. 241-256.

STONE, E. \& Priestley, M. (1996) 'Parasites, pawns and partners: disability research and the role of nondisabled researchers', British Journal of Sociology, 47(4) p. 699-716.

SWAIN J. \& French S. (2004) 'Whose tragedy: towards a personal non-tragedy view of disability', in Swain, J., French, S., Barnes, C. \& Thomas, C. (Eds.), Disabling Barriers - Enabling Environments. (2nd ed.) Sage: London.

TEPPER, M. (2000) 'Sexuality and disability: the missing discourse of pleasure', Sexuality and Disability, 18(4) p. 283-290.

THOMAS, C. (1997) 'The baby and the bath water: disabled women and motherhood in social context', Sociology of Health \& IIIness, 19(5) p. 622-643.

THOMAS, C. (1999) Female Forms: Experiencing and Understanding Disability. Buckingham: Open University Press.

WALBY, S. (2011) 'The impact of feminism on sociology', Sociological Research Online, 16(3) article 21 <http://www. socresonline.org.uk/16/3/21.html>

WAXMAN-FIDUCCIA, B. (1991) 'Hatred: the unacknowledged dimension in violence against disabled people', Sexuality and Disability, 9(3) p. 187-199.

WOODBY, L., Williams B. R., Wittich A. R. \& Burgio K. L. (2011) 'Expanding the notion of researcher distress: the cumulative effects of coding', Qualitative Health Research, 21(6) p. 830-838.

WOTTON, R. \& Isbister, S. (2010) 'A sex worker perspective on working with clients with a disability and the development of touching base', in Shuttleworth, R. \& Sanders, T. (Eds), Sex and Disability: Politics, 
Identity, and Access. Leeds: The Disability Press.

ZAJANO, N. \& Edelsberg, C. M. (1993) 'Living and Writing the Researcher-Researched relationship', Qualitative Studies in Education, 6(2) p. 143-157. 